\title{
A Racionalidade da Dogmática-Penal e sua Função como Estrutura Normativa Garantidora de Liberdades: uma abordagem sistêmica do Direito Penal
}

\author{
The Rationality of Criminal Dogmatic and Their Function as a Freedom \\ Guarantee Normative Structure: an systemic approach to Criminal Law
}

\author{
Daniela Carvalho Almeida da Costa ${ }^{1}$ \\ Elisio Augusto de Souza Machado Júnior ${ }^{1}$ \\ ${ }^{1}$ Universidade Federal de Sergipe (UFS), São Cristóvão, SE, Brasil
}

\begin{abstract}
Resumo: O artigo trata da racionalidade da dogmática-penal e sua importância, segundo uma leitura fundada na teoria dos sistemas, como estrutura normativa que cumpre a função social de garantir liberdades e conter o avanço do poder punitivo. Partindo do debate epistemológico sobre a condição científica, por meio da revisão bibliográfica, o objetivo é analisar a importância que a dogmática-penal assume como critério de racionalização, condicionando a construção do conhecimento à observância de pressupostos teóricos que equacionam a necessidade de tutela de bens jurídicos. Conclui-se que há relevância em reconhecer seu caráter científico como estratégia para lhe conferir maior legitimidade.
\end{abstract}

Palavras-chave: Dogmática-penal. Cientificidade. Garantia de liberdades.
Abstract: The article deals with the rationality of criminal dogmatic and its importance, according to a reading based on systems theory, as a normative framework that fulfills the social function of guaranteeing freedoms and containing the advance of punitive power. Starting from the epistemological debate about the scientific condition, through the bibliographic review, the objective is to analyze the importance that criminal dogmatic assumes as a criterion of rationalization, conditioning the construction of knowledge to the observance of theoretical assumptions that equate the need for the protection of legal assets. It is concluded that there is relevance in recognizing its scientific character as a strategy to give it greater legitimacy.

Keywords: Penal-dogmatic. Scientificity. Guarantee of freedoms.

Recebido em: 02/12/2017

Revisado em: 02/07/2018

Aprovado em: 22/08/2019 


\section{Introdução}

Os estudos científicos do direito penal se dão em bases essencialmente teóricas, o que acaba por explicar a importância dada à dogmática jurídica, da qual uma pesquisa nesta área dificilmente consegue escapar. Tão excessiva é a quantidade de teorias formuladas que, para os estudiosos do direito penal, qualificá-lo como ciência beira à redundância, tamanha a certeza de que efetivamente se produz conhecimento fundado em uma racionalidade de caráter científico.

Continua-se a afirmar o caráter científico como se fosse uma evidência ou dado irrefutável da realidade. Mas quanto a isso não há consenso; pelo contrário, o debate permanece vigente e com força. Tal convicção infundada, por sua vez, esconde uma questão epistemológica ainda mais ampla e que tem sido objeto de constantes debates de correntes de pensamento ao longo da história. Diz ela a respeito do próprio conceito de ciência e quais características podem defini-la, a despeito de sua vagueza, a partir do método de abordagem.

O fato é que já não existe um conjunto de propriedades características capazes de suficientemente designar o que é ciência, deixando em uma zona de penumbra um conjunto de atividades em que a aplicação do termo é vacilante. Ao contrário das ciências naturais, no seio das quais o método científico encontra sua plena aplicabilidade, o objeto de estudo das ciências sociais é variável, seja pela própria mutação social, seja pelo nível de subjetividade decorrente da interpretação do pesquisador. Com base nessa variante, a própria ideia de conhecimento assume um caráter essencialmente dinâmico, de modo a admitir metodologias diferenciadas como validamente aptas a produzi-lo.

No campo do direito, a dificuldade em definir seu objeto é ainda mais evidente, porquanto não se limita àquilo que está positivado ou às construções jurisprudenciais. A comunicação com outras ciências, aliado à função social que o direito cumpre o tornam ainda mais sensível e ampliam sobremaneira o espectro de análise.

Essa vagueza, ao passo em que define sua própria complexidade, não afasta a pertinência da busca pelo caráter científico da dogmática jurídica e 
a contribuição que ela, enquanto esquema racional de pensar o direito, pode dar na estruturação de uma abordagem normativa, porém compromissada com uma perspectiva garantidora, voltada à criação de barreiras de contenção às tentativas de instrumentalização do controle penal.

O problema central de pesquisa consiste em questionar se a dogmática jurídico-penal consegue ir além do cientificismo, com vistas a alcançar um método lógico-racional próprio, cuja função teleológica seja a proteção de bens jurídicos fundamentais. Diante disso, o artigo busca averiguar se a dogmática-penal alcançou uma racionalidade estruturada, cujas consequências se orientam, desde sua gênese, a partir da função de limitar o avanço do poder punitivo; ou se constitui apenas um instrumento voltado à construção retórica de um argumento convincente, sem maior compromisso funcional.

Para tanto, será adotada a teoria dos sistemas como recorte dogmático, partindo-se da hipótese que o Direito Penal tem como finalidade a proteção de bens jurídicos. Nesse contexto, a dogmática-penal assume internamente a função de racionalizar as proposições através de parâmetros de verificabilidade, condicionando externamente, a partir de suas diretrizes teórico-normativas, a produção de conhecimento válido.

Disso se extrai a importância em considerar o direito-penal como ciência, no sentido de legitimar o conhecimento teórico que, por sua vez, assume a função de garantir liberdades frente à necessidade político-criminal de tutela dos bens jurídicos, comunicando ao legislador limites que não devem ser ultrapassados. Para analisar essa hipótese, optou-se pelo raciocínio dedutivo, por meio do método de revisão bibliográfica.

Na primeira parte do artigo será feita uma breve contextualização do tema para, em seguida, abordar a problemática em torno da cientificidade do discurso dogmático, buscando refutar a corrente de pensamento que o considera como atividade racional prática. Em seguida, a partir da transformação do direito em estrutura orientada segundo uma função social, far-se-á uma análise do direito penal como sistema, destacando o papel central que a dogmática jurídico-penal assume nesse contexto de racionalização do poder punitivo. 


\section{A Dogmática Jurídico-Penal para além da Cientificidade}

Conforme salienta Núñez Vaquero (2008, p. 349), a cientificidade da dogmática jurídica foi e continua sendo uma questão controvertida. Embora haja o predomínio do entendimento que lhe atribui uma função prática, a inserção de uma matriz de racionalização como influxo das novas demandas do presente exige uma revisão deste entendimento. Isto importa, sobretudo ao direito penal, haja vista a importância que a dogmática ocupa na estruturação do seu sistema e, em última análise, na proteção de bens jurídicos.

Já não se questiona que o estudo da epistemologia galgou papel de destaque, passando a ter como objeto de análise um espectro de temas inicialmente não compreendidos na investigação acerca do conhecimento científico. Destarte não apenas se emancipou da gnosiologia, como adquiriu identidade como disciplina autônoma, assumindo uma postura reflexiva e crítica a respeito do processo de investigação científica e o conhecimento dele resultante (BUNGE, 1987, p. 5-18). Com efeito, questionar se a dogmática jurídico-penal pode ser identificada como ciência e se é ela capaz de produzir conhecimento a partir de um método lógico-racional próprio, constitui um problema epistemológico em sua essência.

Tal empreitada, entretanto, não pode ser orientada pelos mesmos pressupostos metodológicos de comprovação empírica de uma hipótese. Ao contrário, se deve fazer a necessária adequação às especificidades do conhecimento jurídico, levando em conta seu recorte eminentemente teórico-normativo. Mesmo porque, destaca Richardson (1999, p. 30), as ciências sociais - gênero do qual o direito é espécie - possui características que lhes diferenciam quanto às metodologias que devem ser utilizadas. Cumpre, pois, averiguar se a dogmática, notadamente a dogmática jurídico-penal, pode ser considerada racional, apesar de que não funcione da mesma maneira que o fazem as ciências naturais, e qual a sua função para o direito penal.

A importância em se reconhecer um caráter científico à dogmática jurídico-penal diz respeito à veracidade das teorias por ela produzidas. Uma das principais contribuições do pensamento popperiano, além 
da centralidade do problema na construção do conhecimento objetivo, foi de que podemos aprender com os erros e que eles devem ocupar um papel de destaque. Isso diz respeito à ideia de que as teorias devem ser passíveis de refutação, ou seja, que a produção do conhecimento válido depende do paradoxo de que o valor da verdade reside na sua própria falseabilidade (POPPER, 2004, p. 13-34).

Nessa perspectiva, a cientificidade da dogmática jurídico-penal significa admitir a validade de parâmetros de controle das construções em matéria penal, condicionando, pois, sua legitimidade a partir da verificabilidade segundo critérios teórico-normativos capazes de determinar seu acerto ou desacerto. Do contrário, forçosamente deverá se admitir que qualquer pensamento possa constituir uma teoria, independentemente de sua veracidade segundo critérios metodológicos, e que possa ela servir como argumento para justificar discursos punitivos adversos.

Ao longo da história do pensamento jurídico ocidental, a cientificidade do direito foi sendo aos poucos sistematizada e estruturada. As primeiras tentativas remontam ao século XVI, quando, inspirado pelo conceito racionalista, foram utilizados os moldes metodológicos da ciência moderna para conferir validade ao direito e ao conhecimento por ele produzido. O intento é retomado pelo pensamento positivista do século XIX, segundo o qual apenas um conhecimento objetivo e concludente detém legitimidade que o torna impassível de questionamento. Com efeito, a legitimidade do direito pressupunha a produção de um discurso racional, fundamentado em teorias aceitas e não refutadas.

Partindo da concepção racionalista de ciência, o positivismo jurídico buscou estruturar seu próprio modelo construtivo e dedutivo pautado na legalidade, ao qual denominou de dogmática, com destaque às importantes contribuições de Ihering e Kant (GARCIA, 2011). Mas essa busca por conferir condição científica ao direito sempre foi alvo de fortes críticas, voltadas principalmente à sua concepção dogmática. De modo geral, as objeções se direcionavam à própria vagueza terminológica do que vem a ser o Direito e seu constante diálogo com o poder e a política, sujeitando-se à influência de fatores externos (CARRILLO DE LA ROSA, 2010, p. 40). 
Desde a corrente teórica dialética que se desenvolve na epistemologia do século XX, novos fatores passaram a ser objeto de análise, modificando o eixo das discussões. Ao considerar o homem como ser histórico e social, procurando as causas e os motivos dos fenômenos sociais, um novo modelo de racionalidade prática foi incluído (RICHARDSON, 1999, p. 44-54). Na visão de Carrillo de la Rosa (2010, p. 42), desde então o posto de científico não goza do mesmo prestígio de outrora, vez que ele mesmo não consegue se desvencilhar da própria ambiguidade do seu conceito $^{1}$, ademais relativo quanto ao referencial filosófico adotado.

Não há, pois, um conceito fechado de ciência e um método específico que possa identificá-la. Destarte, não se pode partir das mesmas categorias epistemológicas para questionar acerca da cientificidade do discurso dogmático. Com base nisso, sugere Carrillo de la Rosa (2008, p. 339) que, para superar a encruzilhada da teoria do direito o que se deve questionar não é propriamente o superado caráter científico, mas a racionalidade do discurso jurídico. Para tanto, o autor considera como válida a resposta que vem sendo dada pela moderna teoria da argumentação jurídica, no sentido de que a dogmática deve ser vista como uma atividade racional.

Ferraz Jr. (2015, p. 175-176), ao reconhecer a necessidade da dogmática jurídica recorrer a outros ramos do conhecimento que têm relação com o homem, e reinterpretá-los segundo sua própria necessidade de ordenação, afasta o caráter científico ao concluir que a dogmática jurídica se revela como uma tecnologia com "aspectos de um rito cerimonial". Cumpre à dogmática conferir força e racionalidade ao Direito para elevá-lo acima da arbitrariedade, e desenvolvê-la como ciência, na visão do autor, seria contraproducente, na medida em que aumentaria as angústias sociais a que se busca dar resposta.

Nessa perspectiva, a dogmática assume uma função eminentemente prática que, por meio da teorização, procura oferecer um prognóstico da decisão com base em um raciocínio coerente, guiado pela argumentação. Esse modelo dialético de razão prática, todavia, na medida em que se vol-

${ }^{1} \mathrm{O}$ termo ciência tanto serve para designar o processo metodológico quanto o conteúdo do próprio resultado (CARRILLO DE LA ROSA, 2010, p. 43). 
ta à formação de um discurso persuasivo que intenciona o convencimento do auditório, afasta do caráter científico a atividade da dogmática jurídica, limitando-a à função instrumental de oferecer argumentos para fundamentar uma posição (PERELMANN, 2004).

Há uma clara proeminência da figura do julgador como destinatário dos argumentos apresentados pelas partes em conflito. Isto causa um embaraço teórico ao confundir a função da dogmática jurídica com a da jurisprudência, esta sim essencialmente prática e voltada à solução de um problema concreto. Ocorre que não se pode analisar a atividade do juiz como finalidade última de toda estrutura do Direito e compreender a dogmática jurídica como escada para construir de uma decisão permeada de valores sociais. Ferrajoli (2014, p. 70-71) chama atenção justamente para diferença substancial entre a decidibilidade da verdade processual e a decidibilidade da verdade científica, porquanto esta, diferente daquela, deve guardar observância às técnicas vinculantes no plano normativo para assegurar efetividade no plano prático - observadas, em todo caso, as condições de legitimidade do exercício do poder judicial.

A busca por maior flexibilidade na interpretação dos textos legais, o que em tese facilitaria a resolução do conflito através de uma sentença razoável segundo o caso concreto, pode na prática ocasionar justamente o contrário. Ao contrário do que sustenta Perelman (2004, p. 200), admitir o justo como critério aberto, como argumento retórico para a fundamentação das decisões, implica em admitir uma forte carga ideológica que relativiza qualquer expectativa acerca do próprio conteúdo da decisão, ocasionando insegurança jurídica que pode vir a fundamentar discursos de máxima intervenção. $\mathrm{O}$ direito penal, edificado em princípios basilares à própria teoria do Estado, não deve se abrir ilimitadamente à influência de valores e ideologias, de forte carga moral, porque então se tornaria ele um fenômeno puramente causal e exposto à perniciosa influência de normas de diferente fundamentação.

Por outro lado, o uso da dogmática para fins meramente argumentativos enseja na composição retórica do discurso jurídico, descompromissado com qualquer cientificidade do método utilizado para chegar à decisão como produto acabado. Destaca Freitas (2007, p. 374) o exemplo da 
usual remição, como argumento de autoridade, ao pensamento pinçado de autores de renome, por vezes aos quais se teve acesso somente por fonte indireta. Em casos tais, sem que se demonstre um adequado alinhamento teórico da referência utilizada, há apenas o uso retórico da autoridade representada pelo autor, utilizado sem respaldo metodológico.

Consequentemente, na medida em que não se possa afastar por completo a influência de fatores externos e a humana subjetividade do julgador, a visão da dogmática jurídica como atividade racional abre espaço à discricionariedade argumentativa do seu conteúdo. No campo do direito penal, onde as teorias são legítimas na medida em que reflitam a inviolabilidade de direitos e garantias fundamentais vocacionados à limitação do poder punitivo, o uso eminentemente prático dessa nova dialética não pode suplantar a função que ela deve assumir como ciência.

Em posfácio à sua obra aqui referenciada, Ferraz Jr. (2015, p. 204205) admite que os influxos da globalização e as novas demandas sociais dela advindas justificam uma releitura na abordagem da dogmática jurídica e, com maior razão, da dogmática jurídico-penal, atrelada à manutenção de suas bases garantistas. $\mathrm{O}$ autor observa, na esteira de Habermas e Luhmann, a importância do processo comunicativo e a paulatina transformação do direito em estrutura, tendo em vista o que ele denomina de "função-prognóstico", servindo como prelúdio para posterior adoção de uma visão sistêmica.

\section{A Dogmática Jurídico-Penal como Instrumento de Funcionalidade Sistêmica em Defesa de Bens Jurídicos Fundamentais}

A sumária associação de dogmática jurídica ao conceito de positividade conduz à apressada conclusão de que haveria entre eles aparente equivalência. Ocorre que, a construção legislativa que concretiza o princípio da reserva legal não é propriamente o momento de criação ou origem do Direito, que resulta de elementos causais muito mais complexos. A decisão do legislador, segundo Luhmann (1985, p. 8), "[...] se confronta com uma multiplicidade de projeções normativas já existentes, entre as 
quais ele opta com um grau maior ou menor de liberdade". Tal afirmação indica que existe uma estrutura que condiciona não somente a atuação legislativa e a construção de enunciados normativos, como a própria produção do conhecimento.

Em matéria penal, não se outorga ao legislador liberdade criativa plena ao positivar um valor voltado à tutela de bens jurídicos, como fundamento e limite do direito penal ${ }^{2}$. Ao contrário disso, o processo de positivação é internamente associado à prévia estrutura jurídica, à qual toda reflexão sobre o direito deve se reportar; e externamente condicionado por um filtro de legitimação, pelo qual todas as formulações têm que passar para se tornarem socialmente operantes. Sem olvidar da importância deste aspecto de ordem prática, tem ele como pressuposto a existência da norma posta, cuja elaboração, por sua vez, deve observar os conceitos científicos que permitem a verificabilidade intersubjetiva do Direito. O próprio Ferraz Jr. (2015) faz alusão aos antecedentes atrelados ao próprio saber jurídico, cujos enunciados são responsáveis por estabelecerem diretrizes teóricas a serem perquiridas como critério de racionalização das decisões.

Embora admitida a relevância do filtro social como circunstância variável, isto é, o reflexo da historicidade na positivação do direito, esse elemento de causalidade deve respeitar os critérios científicos pré-existentes para uma modificação válida do sistema jurídico. Com efeito, tal concepção sistemática não deve ceder diante do imediatismo de uma perspectiva puramente casuística e indutiva (AMBÓS, 2008, p. 100). Desse modo, há o condicionamento de que a harmonização comunicativa entre sociedade e direito penal resulte da pressão seletiva exercida pelo tempo $^{3}$, mas que isso se reflita de acordo com os arranjos estruturais e processuais do sistema.

\footnotetext{
${ }^{2}$ Sobre o princípio da proteção de bens jurídicos como fundamento e limite do direito penal, vide Schünemann (2013a, p. 39-68).

${ }^{3}$ A configuração social, quando constante, se reflete na repaginação do direito penal, mantendo através da imposição de pena a expectativa social defraudada. Segundo Jakobs (2004, p. 77), "[...] um direito penal que se dirija contra o arraigado espírito dos tempos, não produz uma coesão com sentido, senão uma mistura de manifestações individuais incoerentes" (tradução livre).
} 
Destarte, a influência do ambiente externo na autopoiese do direito penal, além do aspecto cronológico, deve passar pelo crivo de parâmetros científicos, sob pena de se produzirem normas penais estruturalmente insustentáveis do ponto de vista autorreferencial. Dita contingência, que faz parte do ambiente externo, porquanto não seja uma porta incondicionalmente aberta na barreira que o separa do sistema, não autoriza que se adote todo e qualquer tipo de decisão política na produção legislativa, notadamente quando tenha como escopo restringir liberdades congênitas mediante o complexo processo de tipificação.

O direito positivo, afirma Luhmann (1985, p. 44), “[...] é inevitavelmente um direito politicamente escolhido [...]”, o que não significa sujeitar ao livre arbítrio político as questões jurídicas, como se não existisse no sistema condições de seletividade. Em uma sociedade complexa e multifacetada, não deve haver hierarquia entre sistemas diferenciados, que devem não somente coexistir, mas interagir, segundo seus esquemas de funções, para formação do direito possível. Com efeito, a legítima influência do sistema político sobre o legislativo, naquilo que por sua vez se refira ou afete diretamente o sistema do direito, deve ser condicionada, e reputada ilegítima quando pretenda interferir nos processos de interpretação e aplicação da norma, função exclusiva do judiciário que deve se revestir de neutralidade política (LUHMANN, 1985, p. 45-52).

Na medida em que a dogmática assume uma função estruturante, garantindo homogeneidade científica, limites são naturalmente impostos como requisitos teórico-normativos de validade sistêmica, estabelecendo um fio condutor de racionalidade que deve orientar todo exercício interpretativo das normas. Deste modo, se criam regras previamente acordadas que cumprem uma importante função pedagógica; uma espécie de caráter de linguagem comum que, no campo do direito penal, permite uma conversação hermenêutica, orientando a utilização dos institutos e categorias que o definem (GADAMER, 2015). Por essa razão, existem na dogmática penal elementos ontológicos, quase-lógicos ou, em todo caso, valorativamente neutros e que aspiram validade erga omnes (SILVA SÁNCHEZ, 2010, p. 301). 
Entretanto, há necessidade de precisar o que se entende por dogmática e o papel fundamental que ela cumpre no direito penal. Na esteira de Muñoz Conde (2000, p. 40), trata-se do conjunto de critérios interpretativos e sistematizantes, em parte baseados no direito posto, em parte fundado em elementos filosóficos que vão além do próprio Direito positivado. A síntese exposta neste conceito, inobstante acertado, encobre o complexo papel de ordenar e racionalizar a criação e aplicabilidade em abstrato da norma penal, deslocando o centro do debate para o estrato da tipicidade.

Segundo Ordeig (1970, p. 521), uma das suas funções precípuas é justamente averiguar os pressupostos necessários à imputação de um tipo penal em específico, qual o elemento capaz de identificá-lo e distingui-lo dos demais, delimitando a fronteira entre o comportamento impunível e onde se inicia o penalmente relevante. Desta feita, ao precisar referenciais teóricos, conceituar categorias e definir institutos, a dogmática torna possível o controle dos tipos penais em nível jurídico-científico - tanto previamente, quando ainda em fase de elaboração, estabelecendo um conceito crítico ao legislador (ROXIN, 2014a), quanto no momento em que condutas são a ele subsumidas, na aplicação do direito posto ao caso concreto, evitando com isso a imprevisibilidade das decisões.

Em contraponto, argumentar-se-ia que tal nível de compreensão encontra limites intransponíveis no próprio ordenamento jurídico em que editada a norma penal, restringindo sensivelmente seu alcance. Nesta perspectiva fechada, a construção jurídico-científica deve ser primordialmente dirigida à interpretação do direito nacional e a respectiva codificação que lhe sirva de substrato. Para tanto, se vincula total ou principalmente com base nos preceitos vigentes em cada momento e lugar, admitindo tacitamente uma liberdade irrestrita do legislador na construção de seus conceitos e regulações.

Surge, pois, um obstáculo elementar: saber se é correta uma visão nacionalmente independente da dogmática jurídico-penal ou se é defensável a construção de conhecimentos que se pretendam universais. Acaso se observe as codificações penais de cada Estado, é possível constatar que o desenvolvimento científico não se vincula necessariamente ao direito 
posto e, por esta razão, se compartilha a tese de que a dogmática jurídico-penal não fica adstrita à realidade nacional (SILVA SÁNCHEZ, 2010, p. 300), posto que vai se construindo a partir da compreensão do conhecimento científico produzido em mais de uma realidade social.

Exemplificativamente, as legislações penais não conceituam princípios e institutos elementares à estruturação do delito, resultado de longo período de maturação e desenvolvimento de suas abordagens teóricas. Com efeito, as elaborações dogmáticas não derivam do legislador; inobstante disponha de amplo espaço de discricionariedade na decisão de penalizar uma conduta, tal espaço de escolha encontra limites no modelo ao qual esteja vinculado. Antes de tudo, ao legislador é dada a incumbência de decidir previamente acerca dos possíveis modelos existentes.

Feita a escolha, cumpre à dogmática ou ciência jurídico-penal assinalar, com base no princípio da proibição da negação dos pontos de partida, quais as estruturas lhe servem como fundamento (HIRSCH, 2000). Todas as projeções normativas que pretendem vigência jurídica devem respeitar essas condições, obstando a desestabilização decorrente da direta influência exercida pelos demais sistemas. As expectativas políticas e os valores sociais nelas refletido, mesmo quando possam ser adequadamente captados pelo direito penal, o resultado daí decorrente, inclusive no que tange ao legislador, deve estar em conformidade com o modelo adotado e seus consectários dogmáticos.

Como decorrência do próprio paradigma do Estado Democrático de Direito, de inspiração ocidental, o modelo em geral adotado foi o do direito penal do fato, cabendo à dogmática obter, em relação a este, juízos universais acerca do comportamento punível e seus pressupostos (HIRSCH, 2000, p. 175). Além de estabelecer os fundamentos de legitimidade que devem pautar as decisões judiciais e a produção legislativa, isto proporciona à discussão penal em nível internacional fundamentos comuns, servindo como base à estruturação de um direito penal supranacional cujos contornos, em parte distintos do direito penal nacional, se observam no horizonte como um avanço.

Desse modo, as vantagens de tal concatenação vão além de garantir segurança jurídica e racionalidade das decisões (ORDEIG, 1970). Depre- 
ende-se que a dogmática assume a função de estabelecer uma suficiente linearidade das operações sistêmicas, definindo as unidades próprias que, a um só tempo, identificam o direito penal, diferenciando-o dos demais subsistemas do Direito e do próprio ambiente. Para tanto, ela produz efeito, sobretudo, na formação de significados através de uma linguagem tecnológica conceitual uniforme, isto é, na construção de signos com valor expressivo, como pressuposto do processo comunicativo em nível jurídico-penal (LUHMANN, 2016).

Isso não significa, entretanto, coadunar com a visão puramente instrumental, consoante a superada visão argumentativa. Tanto ao legislador quanto ao operador do direito, a dogmática se apresenta como um conjunto ordenado de conceitos vinculantes, elevando sua capacidade de rendimento como sistema configurado segundo uma racionalidade específica. É inconcebível, por exemplo, a edição de um tipo penal cuja estrutura não observe os elementos gerais da imputação e os limites que lhe são estabelecidos; tal desordem conduziria ao isolamento da norma como consequência de sua incomunicabilidade interna e, ao final, em sua eliminação. De igual modo, constitui uma clara disfunção sistêmica o uso político de tipos penais para, independentemente do fato praticado e da sua relevância, simbolicamente atingir um grupo determinado de indivíduos, cedendo às pressões políticas favoráveis à incriminação.

Por outro lado, pondera Ambós (2008, p. 101), deve haver prudência para que o excessivo refinamento da ciência penal não se converta na contraproducente "hiperdogmatização", hermeticamente fechada e autossuficiente quanto aos seus postulados. É necessário, pois, repensar o seu papel para que ela de fato assuma funcionalidade sistêmica como instrumento de racionalização; neste caso, para que sirva como garantidora da solidez da estrutura teórica e, em última análise, dos direitos fundamentais naturalmente envolvidos sempre que discutida a opção pela criminalização de condutas.

Impõe-se ressalvar que esta funcionalidade não deve estar cegamente vinculada apenas aos próprios elementos normativos do direito penal, desprezando por completo a diferenciação em relação ao ambiente social e sua necessária observação pelo sistema, internamente diferenciado pelo 
processo de reprodução autopoiética. Segundo Luhmann (2016, p. 202), o ambiente não deve ser tido como categoria residual na relação mantida com o sistema. Ao contrário, ela é antes constitutiva, identificando-o e lhe oferecendo dados externos capazes de influenciá-10 ${ }^{4}$.

Nesta medida, a perspectiva estruturalista aqui adotada avança na concepção sistêmica defendida por Jakobs, que tem na inconsequência social sua principal fragilidade - inclusive contrária à própria teoria dos sistemas sociais que lhe serve como referencial teórico. Conquanto se parta da mesma compreensão de que a estrutura normativa cumpre internamente o papel de regularizar expectativas de comportamento nos contatos sociais, admitir a função penal como mera "confirmação da eficácia da norma" (JAKOBS, 2008, p. 26) implicaria desconsiderar a relação mantida com os destinatários desta e, em última análise, o impacto empírico provocado no ambiente.

$\mathrm{O}$ ato de penalizar um comportamento comunica que a sociedade se nega a modificar seus padrões de configuração, mantendo-se firme ao status quo. A pena, na visão de Jakobs (2004, p. 75-77), consiste em uma refutação ao comportamento contrário à existência da norma, assumindo o direito penal a função de estabilizar a validade desta norma, independentemente das consequências psicossociais produzidas. Contudo, ao dispensar questões valorativas e desprezar o conteúdo da norma a ser estabilizada, tal concepção torna estéril qualquer posição crítica, na medida em que tacitamente admite a válida existência de tipos penais que na prática possam implicar em dano a direitos fundamentais indisponíveis (ROXIN, 2014, p.105-108).

Conceber a norma como bem jurídico a ser tutelado, independentemente do seu conteúdo, pode inadvertidamente transformar o direito

\footnotetext{
${ }^{4} \mathrm{O}$ relacionamento do sistema com o meio que o circunda pode ser explicada pelo uso do esquema input/output. O ambiente é responsável por fornecer ao sistema dados que são apreendidos e transformados de acordo sua estrutura interna e novamente projetados de volta como resultado deste processo. O sistema, contudo, segundo suas próprias regulações, é seletivo quanto às características que deve ter o input para ser admitido segundo critérios pré-estabelecidos. Mas ao mesmo tempo se admite a hipótese de que os próprios limites possam ser modificados, como reflexo indireto do input na própria estrutura do sistema (LUHMANN, 2016, p. 228-235).
} 
penal em instrumento motivado por uma agenda político-ideológica que, aproveitando-se do apego normativo acrítico, pode orientar perigosamente o fortalecimento de um funcionalismo penal perverso. A edição de um tipo penal não se legitima apenas como resultado da vontade da maioria formalmente representada, mas como reflexo desta vontade cientificamente limitada por enunciados que traduzam preceitos inderrogáveis e constitucionalmente previstos. No marco de um Estado Democrático de Direito, deve ele funcionar como ferramenta vocacionada à manutenção cogente de expectativas sociais, mas orientada em última instância à “[...] proteção de bens jurídicos frente aos riscos não permitidos" (ROXIN, 2009, p. 61).

Para Schünemann (2013, p. 67), que defende a releitura do princípio da proteção de bens jurídicos compreendido como limitador do direito penal, "a análise do bem jurídico não encerra o trabalho dogmático, muito pelo contrário: apenas o inicia”, tendo em vista que ele decorre, segundo o autor, de uma vinculação constitucional com possibilidade de imposição coativa. Nesse sentido, ele apenas se legitima quando expressar um interesse urgente de convivência pacífica, justificando o apelo ao direito penal por irradiação constitucional, servindo como instrumento para restrição da discricionariedade legislativa. No mesmo sentido são as críticas feitas pelo conceito limitativo ao conceito legitimante de bem jurídico, destacando que a lei penal, dada sua natureza fragmentaria e excepcional, deve ter como pressuposto a afetação de um bem juridicamente tutelado (ZAFFARONI; SLOKAR; ALAGIA, 2002, p. 486-487).

Em que pesem as críticas difundidas ao princípio da proteção de bens jurídicos, sua releitura o mantém fecundo e indispensável enquanto diretriz normativa, que consolida a limitação do direito penal à última razão na defesa de direitos e garantias fundamentais. Essa tarefa atribuída ao direito penal, de salvaguardar bens jurídicos aos quais deve estar constitucionalmente vinculado possui, segundo Baratta (2010, p. 495), “[...] uma função imanente ao sistema do direito penal positivo, e uma função extra-sistemática $[\ldots]$ ", repercutindo também no ambiente. Por esta razão, deve servir como norte para guiar as políticas públicas no atual Estado da segurança, que "[...] seria a forma política que assume a "sociedade de risco"” (BARATTA, 2010, p. 506). 
Essa corrente, denominada funcionalista, adota a premissa metodológica de que o sistema penal deve determinar-se em função do que resulte socialmente adequado, servindo como instrumento, não como molde. Como consequência interna mais decisiva, na tipicidade se contempla o fato desde o ponto de vista da necessidade da pena em abstrato, logo a valoração que se realiza é independente da pessoa do autor e da situação concreta da ação (VALLEJO, 1995). Também nessa perspectiva, a dogmática jurídico-penal assume uma função intra-sistêmica, conferindo validade científica ao direito penal.

De modo tal, as normas que criminalizam condutas são ilegítimas sempre que não protegerem um bem jurídico identificável, o que somente é possível caso se renuncie ao uso de conceitos gerais vagos, restringindo a discricionariedade na definição do injusto. As construções penais, para lograr o posto de teoria, devem não apenas observar esta função social, como passar pelo crivo do método científico consubstanciado no esquema de validade imposto pela dogmática jurídico-penal.

Por outro lado, é igualmente relevante considerar que o controle penal e o exercício do poder punitivo, na prática, operam contra alvos estereotipados, sujeitando-os ao aprisionamento que "[...] reproduz criminalidade, gera reincidência, condiciona patologias psíquicas e reforça papéis desviados como consequência da exigência de assumi-los na vida carcerária" (ZAFFARONI, 2012, p. 441). Nesse sentido, como pondera Andrade (2008, p. 257), é necessário observar os reais resultados da criminalização, as agências de controle, para então saber como a dogmática penal funciona, identificando suas limitações para, de forma isolada, conseguir entregar o funcionamento garantista prometido.

É esse ponto de inflexão que inspira as críticas da concepção redutora desenvolvida por Zaffaroni (2002), cuja visão conglobada não deixa de perquirir a ordenação de um conjunto de requisitos de mínima racionalidade, com o objetivo de estabelecer, no campo metodológico da dogmática penal - sem a qual o direito penal seria convertido em discurso político juridicamente vazio -, mecanismos de contenção do poder punitivo. Com efeito, devem se estabelecer pontes sociológicas e criminológicas de interlocução, a partir das quais seja possível refinar as construções teóri- 
cas, orientando-as teleologicamente para elaborar uma dogmática penal consciente do inevitável caráter político de seus conceitos e, nessa medida, guiada para interferir minimamente na liberdade e garantir a primazia dos direitos fundamentais.

\section{Conclusão}

Quanto mais desenvolvida estiver a dogmática jurídico-penal, mais racionalidade haverá na produção de tipos penais, garantindo também que se observem parâmetros de validade na interpretação e aplicação de um preceito criminalizante. Tal posição, inobstante aparente estar relacionada a um excessivo rigor metodológico, não se vincula aos ultrapassados preceitos do positivismo jurídico, que utopicamente pretendia resolver os problemas jurídicos rechaçando qualquer elemento extralegal.

Nisso reside o sentido e a importância que ainda subjaz em se demonstrar, e não apenas afirmar, seu caráter científico, satisfazendo ao propósito de racionalizar a elaboração teórica de modo a reputar como inválida qualquer construção que não considere, ao fim e ao cabo, a tutela de bens jurídicos. Com efeito, essa função estruturante que cumpre a dogmática jurídico-penal não significa sustentar sua ruptura com a finalidade social que deve cumprir o Direito; ao contrário disto, seu papel internamente desempenhado na visão sistêmica do direito penal é precisamente o que permite sua comunicação com o ambiente.

A principal consequência desta orientação consiste nos limites que ela impõe ao avanço do poder punitivo e ao uso corrente e desarrazoado do direito penal como ferramenta de controle. Não significa, contudo, simplesmente afastar seu aspecto prático, que se mantém tanto na influência externamente exercida quanto em sua utilização como recurso argumentativo no debate jurídico. Inobstante a expectativa que continua a cumprir na formação da jurisprudência, a dogmática jurídico-penal não deve se amoldar à jurisprudência, mas servir de instrumento teleológico ao sistema penal, apontando-lhe finalidade atrelada à proteção de bens jurídicos fundamentais. Apesar das posições em sentido contrário, ela possui espaço e função próprios, servindo como parâmetro teórico de veraci- 
dade e falseabilidade das proposições, razão pela qual a ela não se pode negar seu caráter científico.

Tal cientificidade, conquanto inegavelmente importante, não deve desconsiderar ou menosprezar as críticas que lhe cabem ser feitas. A dogmática penal deve ser encarada como parte da Ciência Penal, sendo esta compreendida como o conjunto de saberes científicos relacionados ao conhecimento do crime e do sistema penal. Como parte, ela é por certo insuficiente, devendo dialogar com os demais sistemas para, consciente das suas limitações metodológicas, melhor entregar um instrumento capaz de dar efetiva contribuição para fundamentar uma concepção limitadora do poder punitivo.

\section{Referências}

AMBÓS, Kai. Dogmática jurídico penal y concepto universal del hecho punible. In: GARCÍA VALDÉS, Carlos et al. (coord.). Estudios penales en homenaje a Enrique Gimbernat. Madrid: Edisofer, 2008. p. 97-124. ANDRADE, Vera Regina Pereira de. Construção e identidade da dogmática penal: do garantismo prometido ao garantismo prisioneiro. Revista Seqüência, Florianópolis, v. 29, n. 57, 2008. Disponível em: http://periodicos.ufsc.br/index.php/sequencia/article/view/14956. Acesso em: 9 jul. 2019.

\section{BARATTA, Alessandro. Criminologia crítica e crítica ao direito penal:} introdução à sociologia do direito penal. Trad. Juarez Cirino dos Santos. 6. ed. Rio de Janeiro: Renavan - Instituto Carioca de Criminologia, 2014. BUNGE, Mario. Epistemologia: curso de atualização. Tradução: Claudio Navarra. 2. ed. São Paulo: T. A. Queiroz da Universidade de São Paulo, 1987.

CARRILLO DE LA ROSA, Yezid. De la cientificidad a la racionalidad del discurso dogmático jurídico: el puesto de la razón prática em la dogmática jurídica. Revista Telemática de Filosofía del Derecho, Madrid, n. 11, p. 335-348, 2007/2008. 
CARRILLO DE LA ROSA, Yezid. Cientificidad en las ciencias jurídicas y sociales. Saber, Ciencia y Libertad, Cartagena, v. 5, n. 2, p. 39-52, jun. 2010.

FERRAJOLI, Luigi. Direito e razão: teoria do garantismo penal.

Tradução: Ana Paula Z. Sica, Fauzi H. Choukr, Juarez Tavares e Luís F. Gomes. 4. ed. São Paulo: Revista dos Tribunais, 2014.

FERRAZ JR., Tercio Sampaio. Função social da dogmática jurídica. 2. ed. São Paulo: Atlas, 2015.

GADAMER, Hans-Georg. Verdade e método: traços fundamentais de uma hermenêutica filosófica. Tradução: Flávio Paulo Meurer. 15. ed.

Petrópolis: Vozes, 2015.

GARCIA, Silvana Mabel. El derecho como ciência. Revista de la Universidad del Centro Educativo Latinoamericano, Rosario (Argentina), v. 14, n. 26, p. 13-38, jun. 2011.

JAKOBS, Günther. Dogmática de derecho penal y la configuración normativa de la sociedad. Trad. Jacobo López Barja de Quiroga. Madrid: Civitas Ediciones, 2004.

JAKOBS, Günther. Tratado de direito penal: teoria do injusto penal e culpabilidade. Tradução: Gercélia Batista de O. Mendes e Geraldo de Carvalho. Belo Horizonte: Del Rey, 2008.

LUHMANN, Niklas. Sociologia do direito. Tradução: Gustavo Bayer. Rio de Janeiro: Tempo Brasileiro, 1985. v. II.

LUHMANN, Niklas. Sistemas sociais: esboço de uma teoria geral. Tradução: Antônio C. Luz Costa, Roberto D. Torres Júnior e Marco Antonio dos S. Casanova. Petrópolis: Vozes, 2016.

MUÑOZ CONDE, Francisco. Presente y futuro de la dogmática jurídico penal. In: GIORGI, Raffaele de (org.). Il diritto e la differenza. Lecce: Pensa Multimedia, 2002. p. 463-475.

NUÑEZ VAQUERO, Álvaro. La cientificidad de la dogmática jurídica: sobre Carrillo de la Rosa. Revista Telemática de Filosofía del Derecho, Madrid, n. 11, p. 349-363, 2007/2008. 
ORDEIG, Enrique Gimbernat. ¿Tiene un futuro la dogmática juridicopenal? In: Problemas actuales de las ciencias penales y de la filosofía del derecho: libro en homenaje al profesor Jiménez de Asúa. Buenos Aires: Ediciones Panedille, 1970. p. 495-523.

PERELMAN, Chaïm. Lógica jurídica: nova retórica. Tradução: Virgínia K. Pupi. Revisão da tradução: Maria Ermantina de A. P. Galvão; Revisão técnica: Gildo Sá L. Rios. 2. ed. São Paulo: Martins Fontes, 2004.

POPPER, Karl Raymund. Lógica das ciências sociais. Tradução: Estevão de R. Martins. 3. ed. Rio de janeiro: Tempo Brasileiro, 2004. RICHARDSON, Roberto Jarry. Pesquisa social: métodos e técnicas. São Paulo: Atlas, 1999.

ROXIN, Claus. A proteção de bens jurídicos como função do direito penal. Tradução e organização: André Luís Callegari e Nereu José Giacomolli. 2. ed. Porto Alegre: Livraria do Advogado, 2009.

ROXIN, Claus. O conceito de bem jurídico crítico ao legislador em xeque. In: ROXIN, Claus. Novos estudos de direito penal. Organização: Alaor Leite. São Paulo: Marcial Pons, 2014. p. 70-97.

ROXIN, Claus. Reflexões sobre a construção sistemática do direito penal. In: ROXIN, Claus. Novos estudos de direito penal. Organização: Alaor Leite. São Paulo: Marcial Pons, 2014. p. 98-115.

SILVA SÁNCHEZ, Jesús-Maria. El derecho penal ante la globalizacion y la integracion supranacional. In: FRANCO, Alberto Silva; NUCCI, Guilherme de Souza. Doutrinas essenciais: direito penal. São Paulo: Revista dos Tribunais, 2010, v. 1.

SCHÜNEMANN, Bernd. O princípio da proteção de bens jurídicos como ponto de fuga dos limites constitucionais e da interpretação dos tipos. In: SCHÜNEMANN, Bernd. Coordenação: Luís Greco. Estudos de direito penal, processual penal e filosofia do direito. São Paulo: Marcial Pons, 2013. p. 39-68.

VALLEJO, Manuel Jaén. Los puntos de partida de la dogmática penal. Anuario de Derecho Penal y Ciencias Penales, Madrid, n. 48, f. 1, p. 57-70, 1995. 
ZAFFARONI, Eugenio Raúl. A palavra dos mortos: conferências de criminologia cautelar. Tradução: Sérgio Lamarão. São Paulo: Saraiva, 2012.

ZAFFARONI, Eugenio Raúl; SLOKAR, Alejandro; ALAGIA, Alejandro. Derecho penal: parte general. 2. ed. Buenos Aires: Ediar, 2002.

Daniela Carvalho Almeida da Costa é doutora em Direito pela Universidade de São Paulo. Mestre em Direito pela Universidade de São Paulo. Professora do quadro permanente da Universidade Federal de Sergipe (UFS), lecionando na graduação e no Programa de Pós-graduação em Direito - Mestrado (PRODIR/ UFS). Professora da Escola da Magistratura de Sergipe. Membro da Comissão Executiva e de Articulação Institucional para difusão da Justiça Restaurativa no Estado de Sergipe.

E-mail: dancacosta@hotmail.com

Endereço profissional para correspondência: Universidade Federal de Sergipe, Programa de Pós-Graduação em Direito, Av. Marechal Rondon, s/n, Bairro Jardim Rosa Elze, São Cristóvão, SE. CEP: 49100-000.

Elisio Augusto de Souza Machado Júnior é mestre em Direito pela Universidade Federal de Sergipe (PRODIR/UFS). Graduado em Direito pela Universidade Federal de Sergipe. Pesquisador vinculado ao Grupo de Pesquisa "Estudos sobre violência e criminalidade na contemporaneidade". Advogado.

E-mail: elisio_machado@hotmail.com

Endereço profissional: Rua Tênisson Ribeiro, n. 114, Salgado Filho, Aracaju, SE. CEP: 49020-370. 